\title{
LATERAL BUCKLING ANALYSIS OF ANGLED FRAMES WITH THIN-WALLED I-BEAMS
}

Jong-Dar Yau

Department of Architecture, Tamkang University, Taipei, Taiwan., jdyau@mail.tku.edu.tw

Follow this and additional works at: https://jmstt.ntou.edu.tw/journal

Part of the Civil and Environmental Engineering Commons

\section{Recommended Citation}

Yau, Jong-Dar (2009) "LATERAL BUCKLING ANALYSIS OF ANGLED FRAMES WITH THIN-WALLED I-BEAMS," Journal of Marine Science and Technology. Vol. 17: Iss. 1, Article 5.

DOI: 10.51400/2709-6998.1974

Available at: https://jmstt.ntou.edu.tw/journal/vol17/iss1/5

This Research Article is brought to you for free and open access by Journal of Marine Science and Technology. It has been accepted for inclusion in Journal of Marine Science and Technology by an authorized editor of Journal of Marine Science and Technology. 


\section{LATERAL BUCKLING ANALYSIS OF ANGLED FRAMES WITH THIN-WALLED I- BEAMS}

\section{Acknowledgements}

The author would like to thank the valuable comments of reviewers for this paper. Part of the illustrative examples in this study is modified from the extended abstract entitled "Out of plan buckling of angled frames with warping effect," presented at the 9th U.S. National Congress on Computational Mechanics, San Francisco, July 23-26, 2007 [7]. 


\title{
LATERAL BUCKLING ANALYSIS OF ANGLED FRAMES WITH THIN-WALLED I-BEAMS
}

\author{
Jong-Dar Yau*
}

Key words: angled frame, lateral buckling, non-uniform torsion.

\begin{abstract}
With the inclusion of warping deformations, lateral buckling behavior for angled frames with I-beams under the action of in-plan bending moments will be conducted in this paper. By adopting the joint equilibrium for the angled frame and the force-displacement relations for the members defined at the buckled position (rather than the initial position), the analytical solutions for buckling moments of an angled frame with simply supported ends are presented in closed form. The computed results indicate that for symmetric buckling, the buckling resistance to resist positive moments can be strengthened along with the increase of inclined angle of the member of an angled frame, but the buckling resistance against negative moments is reduced. On the other hand, for anti-symmetric buckled modes, the buckling strength to carry positive moments generally rises with the increase of inclined angles. However, an interesting phenomenon indicates that the buckling capacity to resist negative moments may reach its minimum at certain inclined angles. It means that the rotational restraints of torsion and bending at the joint of such a critical angled frame are situated in a minimum state to resist the anti-symmetric buckled modes.
\end{abstract}

\section{INTRODUCTION}

Previous research on the lateral buckling of angled frames with solid section under in-plane bending moments can be tracked back to the analytical works by Yang and Kuo [4, 5]. They reported that the force-displacement relations for the members need be defined in the buckling position, rather than the initial position. However, the physical phenomena of buckling behavior and the parametric studies of buckling moments for an angled frame with various subtended angles were not discussed in their studies. Moreover, the effect of warping for thin-walled beams is usually taken into account on buckling analysis in steel structural design for its properties of light weight and load-carring capacity undergoing large deformations within elastic range, especially for a structure with slender members. Thus, this paper can be regarded as an extension of

Paper submitted 09/04/07; accepted 01/15/08. Author for correspondence: Jong-DarYau (e-mail: jdyau@mail.tku.edu.tw).

* Department of Architecture, Tamkang University, Taipei, Taiwan. the previous work done by Yang and Kuo [4, 5].

Adopting the joint equilibrium of an angled frame including warping and utilizing the force-displacement relations for the members expressed at the buckled position (rather than the initial position), one can obtain a set of analytical solutions of critical loads with symmetric or anti-symmetric buckled modes in closed form. The analytical results indicate that for symmetric buckled modes, the capacity to resist positive buckling moments (see Fig. 1) will be strengthened along with the increase of inclined angles of an angled frame, but the buckling resistance in negative moments is reduced. On the other hand, considering another case for anti-symmetric buckled modes, the capacity to carry negative buckling moments generally rises along with the increase of inclined angles. However, the positive buckling moments of fundamental anti-symmetric buckled mode for an angled-frame with various inclined angles may reach its minimum at a certain angle. It means that the joint of the angled frame with such a critical inclined angle can merely provide a minimum partial rotational restraint to resist anti-symmetric buckling. Moreover, according to the present study in buckling analysis for a buckled angled frame with various warping rigidities, the strengthening effect of higher warping rigidities on the positive critical moments of symmetric buckled modes is of insignificance. It is attributed to the fact that the buckling resistance of positive moments for the symmetric buckled modes of a simply supported angled-frame decays significantly along with the increase of inclined angles.

\section{GOVERNING EQUATIONS}

Prior to the formulation of governing equation and boundary conditions for an angled frame with uniform thin-walled I-sections, some basic assumptions are adopted in this study [1-3]: (1) The I-section is bi-symmetric; (2) The material is linear, isotropic and homogeneous; (3) The thin-walled I-beam is slender; (4) The I-beams constituting the angled frame are identical; (5) The angled frame investigated herein is symmetric about its central line and is simply supported both in and out of its own plane; (6) The applied moment $M_{y}$ is defined as a positive moment along the direction of $+y$ axis depicted in Fig. 1, and the negative moment along the direction of $-y$ axis.

Figure 1 shows a simply supported angled-frame lies in the plane $(x, z)$ and undergoes the action of uniform bending moments $\left(M_{y}\right)$ about the major principle axis of the I-section. The 


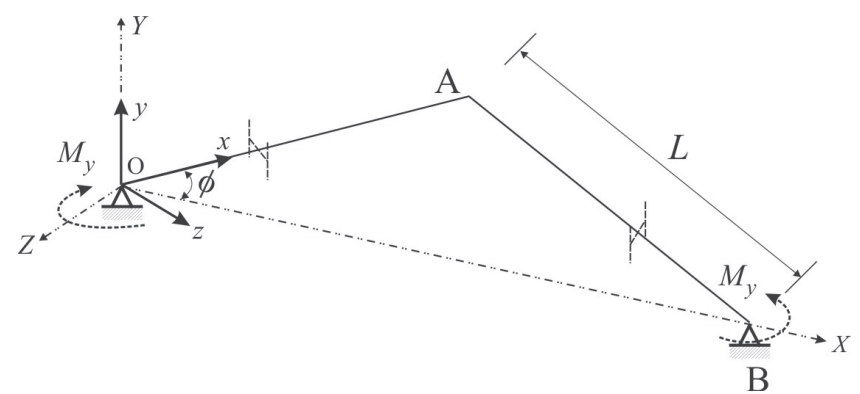

Fig. 1. Angled frame under in-plane bending moments.

lateral buckling equations including non-uniform torsion described in local coordinate system $(x, y, z)$ for the left I-beam of the angled frame shown in Fig. 1 are given by $[1,4,5]$ :

$$
\begin{gathered}
E I v^{\prime \prime \prime}+M_{y} \theta_{x}{ }^{\prime}=0 \\
E C_{\omega} \theta_{x}{ }^{\prime \prime}-G J \theta_{x}{ }^{\prime}+M_{y} v "=0
\end{gathered}
$$

where the prime ${ }^{\prime}=\partial(\bullet) / \partial x, L=$ beam length of each member of the frame, $E$ = elastic modulus, $G=$ shear modulus, $I=$ moment of inertia about $\mathrm{z}$-axis, $J=$ torsional constant, $C_{\omega}=I_{f} \times h^{2} / 2=$ warping constant, $I_{f}=$ flange moment of inertia about $y$-axis, $h=$ depth of I-section, $v=$ deflection in the direction of out of plane, and $\theta_{x}=$ torsional rotation along the local beam axis $x$. The geometric and natural boundary conditions at the left simple support end of the angled frame are

$$
\begin{gathered}
v(0)=\theta_{x}(0)=0 \\
E I v^{\prime \prime}(0)=E C_{\omega} \theta_{x} "(0)=0
\end{gathered}
$$

and the internal forces of flexural shear, torque, bending moment, and warping moment at the joint $\mathrm{A}$ in deformed configuration are expressed as the following natural boundary conditions $[6,7]$

$$
\begin{gathered}
{ }^{2} F_{y}(L)=-E I v^{\prime \prime}-M_{y} \theta_{x}{ }^{\prime} \\
{ }^{2} M_{x}(L)=G J \theta_{x}{ }^{\prime}-E C_{\omega} \theta_{x}{ }^{\prime \prime}-M_{y} \theta_{x} \\
{ }^{2} M_{z}(L)=E I v^{\prime \prime}+M_{y} \theta_{x} \\
{ }^{2} B_{y}(L)=E C_{\omega} \theta_{x} "
\end{gathered}
$$

Here, the superscript 2 means the deformed configuration as the angled frame buckled. Solving the simultaneous differential equations in (1) and (2) with the homogeneous boundary conditions in (3) and (4) yields the following general solutions:

$$
\begin{gathered}
\theta_{x}=A_{1} \sinh \alpha_{1} x+A_{2} \sin \alpha_{2} x+A_{3} x \\
v=\left[\frac{-A_{2}}{\alpha_{1}^{2}} \sinh \alpha_{1} x+\frac{A_{4}}{\alpha_{2}^{2}} \sin \alpha_{2} x\right] \alpha+A_{4} x
\end{gathered}
$$

where $\left.A_{i}\right|_{i=1 \sim 4}=$ undetermined coefficients, $\alpha=M_{y} / E I$, and

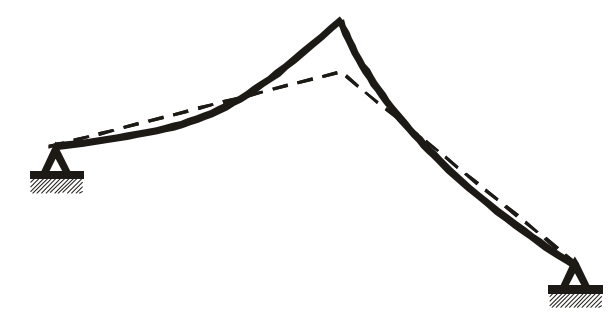

Fig. 2. Lateral buckling of angled frames with symmetric mode.

$$
\begin{aligned}
& \alpha_{1}=\sqrt{\frac{G J}{2 E C_{\omega}}+\sqrt{\left(\frac{G J}{2 E C_{\omega}}\right)^{2}+\frac{M_{y}^{2}}{E I E C_{\omega}}}} \\
& \alpha_{2}=\sqrt{\frac{-G J}{2 E C_{\omega}}+\sqrt{\left(\frac{G J}{2 E C_{\omega}}\right)^{2}+\frac{M_{y}^{2}}{E I E C_{\omega}}}}
\end{aligned}
$$

According to the symmetric properties of the angled-frame studied here, the buckled modes of this frame can be divided into two types: the symmetric and anti-symmetric buckling. Based on the symmetric/anti-symmetric behaviors of a symmetric structural system, only the left member of the angled frame is employed to derive the characteristic equations of buckling.

\section{BUCKLING ANALYSIS}

Before investigating the buckling loads of an angle frame under in-plan bending moments, the following data are assumed: $E / G=2.6, h / L=0.1$.

\section{Symmetric Buckling}

As shown in Fig. 2, let us consider the symmetric properties of a buckling angled frame, the continuity conditions at joint $\mathrm{A}$ in buckled position are given by $[4,5]$

$$
\begin{gathered}
v^{\prime}(L) \cos \phi-\theta_{x}(L) \sin \phi=0 \\
{ }^{2} F_{y}(L)=0 \\
{ }^{2} M_{x}(L) \cos \phi+{ }^{2} M_{z}(L) \sin \phi=0
\end{gathered}
$$

and

$$
\theta_{x}^{\prime}(L) \cos \phi+v^{\prime \prime}(L) \sin \phi=0
$$

It is noted that the continuity condition in (16) represents the joint A would behave like a warping prevented end in the global $X$-direction due to the property of symmetric buckled modes. Substituting (5)-(7) into (9) and (10) and adopting the continuity conditions in (13)-(16), one can obtain the following characteristic equation of buckling:

$$
\begin{aligned}
& \cos \left(\alpha_{2} L\right)\left[\alpha_{1}\left(\alpha_{2}^{2}-\alpha^{2}\right) \tanh \left(\alpha_{1} L\right) \sin \phi\right. \\
& \left.+\alpha\left(\alpha_{1}^{2}+\alpha_{2}^{2}\right) \cos \phi\right]=\alpha_{2}\left(\alpha_{1}^{2}+\alpha^{2}\right) \sin \left(\alpha_{2} L\right) \sin \phi
\end{aligned}
$$




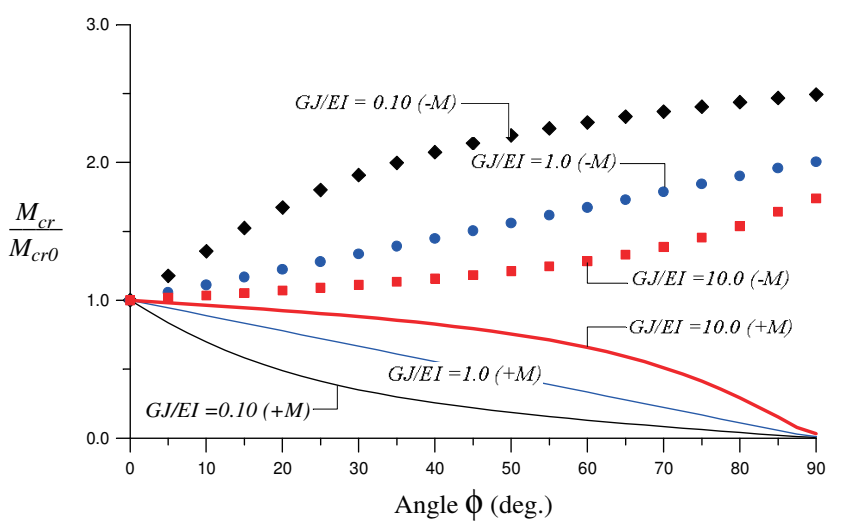

Fig. 3. Buckling moments on angled frames: symmetric modes.

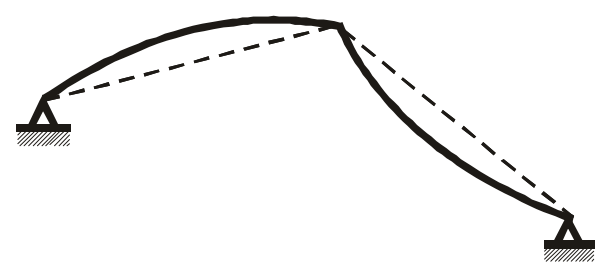

Fig. 4. Lateral buckling of angled frames with anti-symmetric mode.

For a given inclined angle $\phi$, the critical moment $M_{c r}$ of symmetric buckled modes for the angled frame with uniform I-beams can be obtained by solving the characteristic equation shown in (17). On the other hand, let us consider a special case of $\phi=0$, the angled frame can be reduced to a simple beam with length $2 L$ and then (17) becomes $\cos \left(\alpha_{2} L\right)=0$. Thus, the fundamental buckling moment of symmetric mode reduces to

$$
M_{c r 0}= \pm \frac{\pi}{2 L} \sqrt{E I G J}\left(1+\frac{\pi^{2} E C_{\omega}}{4 L^{2} G J}\right)^{1 / 2}
$$

The critical moment in (18) agrees exactly with the closed form solution given by references [4-6].

Figure 3 shows the critical moments against various inclined angles $\phi$. As expected, all the magnitudes of negative buckling moments are larger than those of the positive ones. And the positive buckling moments decay rapidly along with the increase of inclined angles since the angled frames with simply supported ends may become an unstable structure as the inclined angle approaches to a right angle. From the response curves of critical moments against various inclined angles $\phi$ associated with different ratios of $G J / E I$, it can be seen that decreasing the rigidity ratio of $G J / E I$ may reduce the buckling strength to carry positive moments, and increase the negative critical moments of symmetric buckled modes. In other words, for symmetric modes of a simply supported angled-frame with uniform I-beams, increasing the torsional rigidity can strengthen the buckling resistance of positive moments, but the capacity to resist negative buckling moments is reduced.

\section{Anti-symmetric Buckling}

Considering the anti-symmetric buckled modes of the angled

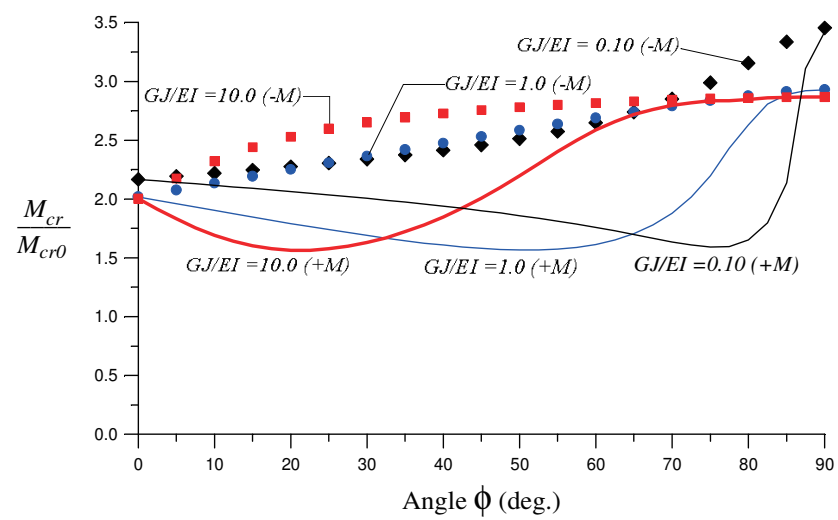

Fig. 5. Buckling moments on angled frames: anti-symmetric modes.

frame depicted in Fig. 4, the continuity conditions at joint A established in deformed configuration should satisfy the following boundary conditions $[4,5]$ :

$$
\begin{gathered}
v(L)=0 \\
\theta_{x}(L) \cos \phi+v^{\prime}(L) \sin \phi=0 \\
M_{z}(L) \cos \phi-M_{x}(L) \sin \phi=0
\end{gathered}
$$

and the property of anti-symmetric buckled mode at joint $\mathrm{A}$ yields the warping free condition in the global $X$-direction as

$$
\theta_{x}{ }^{\prime}(L) \cos \phi+v^{\prime \prime \prime}(L) \sin \phi=0
$$

Introducing the displacement functions given by (9) and (10) and the internal forces shown in (5)-(8) into the preceding continuity conditions of (19)-(22), one can derive the following characteristic equation with a determinant form

$$
-\frac{\sinh \alpha_{1} L}{\alpha_{1}^{2}} \alpha
$$

$\frac{\sinh \alpha_{1} L}{\tan \phi}-\frac{\alpha \cosh \alpha_{1} L}{\alpha_{1}}$

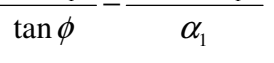

$\alpha_{1}^{2} \sinh \alpha_{1} L$

$-\alpha \alpha_{1} \tan \phi \times \cosh \alpha_{1} L$

$$
\frac{\sin \alpha_{2} L}{\alpha_{2}^{2}} \alpha
$$

$\frac{\sin \alpha_{2} L}{\tan \phi}+\frac{\alpha \cos \alpha_{2} L}{\alpha_{2}}$

$-\alpha \alpha_{2} \tan \phi \times \cos \alpha_{2} L$ $-\alpha_{2}^{2} \sin \alpha_{2} L$

Consider the special case of $\phi=0$, the angled frame is reduced to a simply supported beam with length $2 L$ and (23) becomes $\sin \left(\alpha_{2} L\right)=0$. Thus, the buckling moment of fundamental anti-symmetric mode is reduced to:

$$
M_{c r 1}= \pm \frac{\pi}{L} \sqrt{E I G J}\left(1+\frac{\pi^{2} E C_{\omega}}{L^{2} G J}\right)^{1 / 2}
$$

The buckling load in (24) for a simply supported beam with doubly symmetric I-sections subjected to uniform bending moments coincides exactly with the result given in references [4-6]. 


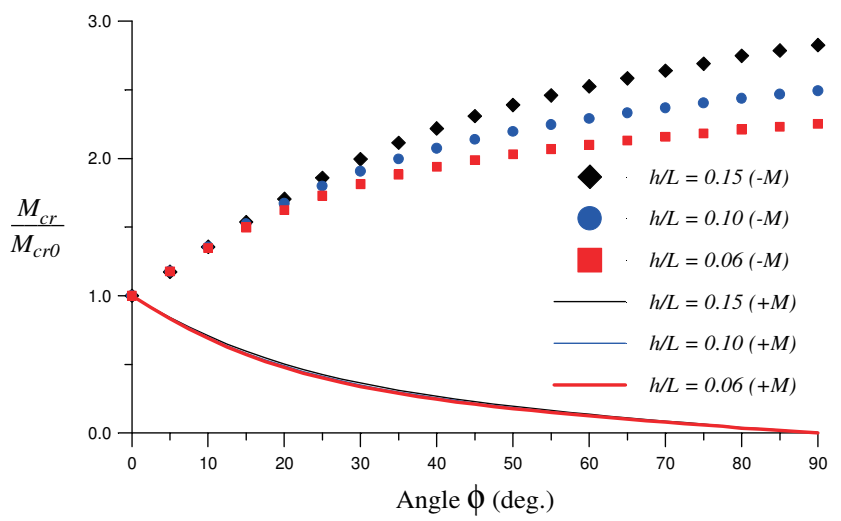

Fig. 6. Effect of warping on angled frames: symmetric modes.

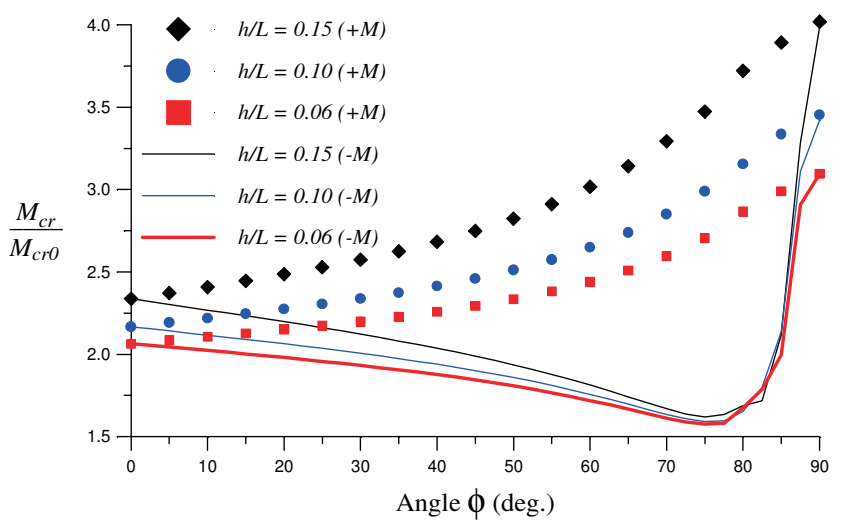

Fig. 7. Effect of warping on angled frames: anti-symmetric modes.

Considering different ratios of $G J / E I$ and solving the characteristic equation shown in (23) for anti-symmetric modes by a numerical method with trial and error, one may obtain the critical moments of $M_{c r}$ against various inclined angles $\phi$, as plotted in Fig. 5. The response curves of critical loads indicate that there exists a minimum value for each response curve of positive buckling moments. It means the boundary restraints at joint A of the angled-frame may attain a minimum state to resist the positive buckling moment of anti-symmetric modes. On the other hand, increasing the rigidity ratio GJ/EI may lead to the minimum positive buckling moment approaching to a lower inclined angle. This fact means that at the joint of an angled frame with lower inclined angles, the torsional restraint to resist lateral buckling strength of anti-symmetric modes plays a more important role than the flexural restraint.

\section{Effect of Warping Rigidities}

As the definition of warping constant for a bi-symmetric I-sections described previously, that is, $C_{\omega}=I_{f} \times h^{2} / 2$, the warping constant is generally dependent on the web-depth $(h)$ of I-section and the flange moment of inertia $\left(I_{f}\right)$. Thus, the selection of an I-section with larger web-depths may directly strengthen the warping capability of an I-beam. For this reason, the ratio of web-depth to beam-length is employed as an indi- cator of an I-beam against warping resistance in this illustrated example, that is, the more the web-depth, the larger the warping constant will be. To demonstrate the effect of warping on the buckling strength of an angled frame under uniform bending moments, let us consider the case that the ratio of $G J / E I$ is set to be 0.1 , and the ratios of web-depth to beam-length are selected as $h / L=0.06,0.10$, and 0.15 , respectively. The calculated results for the critical moments of symmetric and anti-symmetric modes against various inclined angles have been plotted in Figs. 6 and 7 , respectively.

Generally speaking, increasing the web-depth of an I-beam (that is, the larger warping constant) may provide the angled frame more capability to resist lateral buckling. However, as shown in Fig. 6, the increase of web-depth (or warping constant) of I-sections may not provide significant strengthening on the resisting positive buckling moments of symmetric modes. The reason is attributed to the fact that increasing the inclined angle of an angled frame may lead the positive buckling strength to decay rapidly, which can be also observed from the response curves shown in Fig. 7.

\section{CONCLUDING REMARKS}

In this paper, the closed form solutions of buckling bending moments for a simply supported angled-frame with uniform I-section were presented in an analytical way. The results demonstrate that the capacity to resist negative buckling moments for symmetric buckled modes can be strengthened along with the increase of inclined angles of an angled frame, but the buckling resistance to carry positive moments is reduced. The buckling resistance against anti-symmetric buckled modes, it generally rises with the increase of inclined angles. However, its buckling strength to carry positive moments may reach minimum at certain inclined angles, in that the joint of such a critical angled frame can only provide a minimum partial restraint to resist anti-symmetric buckling.

On the other hand, increasing the warping rigidity of an I-section may strengthen the buckling resistance for the angled frame with simple ends. However, the buckling resistance to carry positive moments of symmetric modes for an angled frame with higher warping rigidities cannot be strengthened significantly due to the fact that increasing the inclined angle of an angled frame yields the positive buckling strength of symmetric modes to decay rapidly.

\section{ACKNOWLEDGMENTS}

The author would like to thank the valuable comments of reviewers for this paper. Part of the illustrative examples in this study is modified from the extended abstract entitled "Out of plan buckling of angled frames with warping effect," presented at the 9th U.S. National Congress on Computational Mechanics, San Francisco, July 23-26, 2007 [7]. 


\section{REFERENCES}

1. Chen, W. F. and Atsuta, T., Theory of Beam-Columns, Vol. 2: Space Behavior and Design, McGraw-Hill, New York (1977).

2. McGuire, W., Steel Structures, Prentice-Hall, New Jersey (1968).

3. Timoshenko, S. P. and Gere J. M., Theory of Elastic Stability, 2nd ed., McGraw-Jill, New York (1962).

4. Yang, Y. B. and Kuo, S. R., "Frame buckling analysis with full consideration of joint equilibrium," Journal of Engineering Mechanics, ASCE,
Vol. 118, No. 5, pp. 871-889 (1992).

5. Yang, Y. B. and Kuo, S. R., Theory \& Analysis of Nonlinear Framed Structures, Prentice Hall, Singapore (1994).

6. Yau, J. D., "Elastic stability of I-columns subjected to compressions and bi-moments," Journal of the Chinese Institute of Engineers, Vol. 30, No. 4, pp. 569-578 (2007).

7. Yau, J. D. and Kuo, S. R., "Out of plan buckling of angled frames with warping effect," Abstracts of the 9th U.S National Congress on Computational Mechanics, San Francisco (2007). 